\title{
Pseudopregnancy in goats: Sonographic prevalence and associated risk factors in Khartoum State, Sudan
}

\author{
Areeg Mohamed Almubarak ${ }^{1}$, Naglaa Abd Elhakeem Abass ${ }^{2}$, Majdi Elnaim Badawi ${ }^{1}$, Mohamed Tagelddin Ibrahim³
} Abdelhamid Ahmed Elfadil ${ }^{2}$ and Rihab Mohamed Abdelghafar ${ }^{1}$

1. Department of Veterinary Medicine and Animal Surgery, College of Veterinary Medicine, Sudan University of Science and Technology, P.O. Box 204, Hilat Kuku, Khartoum North, Sudan; 2. Department of Preventive Medicine and Public Health, College of Veterinary Medicine, Sudan University of Science and Technology, P.O. Box 204, Hilat Kuku, Khartoum North, Sudan; 3. Department of Animal Production Science and Technology, College of Science and Technology of Animal Production, Sudan University of Science and Technology, P.O. Box 204, Hilat Kuku, Khartoum North, Sudan.

Corresponding author: Areeg Mohamed Almubarak, e-mail: areegalmubarak@yahoo.com

Co-authors: NAA: naglaa.abass77@gmail.com, MEB: majdi5us@yahoo.com, MTI: tropanimprod@yahoo.com, AAE: abdelhamidelfadil@yahoo.co.uk, RMA: rehabeen@gmail.com

Received: 27-12-2017, Accepted: 07-03-2018, Published online: 23-04-2018

doi: 10.14202/vetworld.2018.525-529 How to cite this article: Almubarak AM, Abass NA, Badawi ME, Ibrahim MT, Elfadil AA, Abdelghafar RM (2018) Pseudopregnancy in goats: Sonographic prevalence and associated risk factors in Khartoum State, Sudan, Veterinary World, 11(4): 525-529.

\begin{abstract}
Aim: This study was conducted to estimate the prevalence of pseudopregnancy in goats and to investigate potential risk factors associated with the condition in Khartoum State.

Materials and Methods: A cross-sectional study was carried out from March 2015 to February 2016. A total of 378 female goats which presented to the Veterinary Teaching Hospital, College of Veterinary Medicine, Sudan University of Science and Technology, for routine ultrasonographic pregnancy diagnosis were examined. Ultrasound scanning was performed using a real-time scanner equipped with dual-frequency (3.5-5 MHz) curvilinear transducer.

Results: The results showed that the prevalence of pseudopregnancy in goats in Khartoum State was $10.6 \%$. Risk factors such as general body condition $\left(\chi^{2}=5.974 ; \mathrm{p}=0.05\right)$, age $\left(\chi^{2}=11.760 ; \mathrm{p}=0.0129\right)$, type of estrus $\left(\chi^{2}=12.794 ; \mathrm{p}=0.000\right)$, and previous reproductive performance $\left(\chi^{2}=13.397 ; \mathrm{p}=0.020\right)$ showed significant association $(\mathrm{p} \leq 0.05)$ with the occurrence of pseudopregnancy in the univariate analysis. Breed $\left(\chi^{2}=12.627 ; \mathrm{p}=0.082\right)$, milk yield $\left(\chi^{2}=5.951 ; \mathrm{p}=0.114\right)$, type of feeding $\left(\chi^{2}=1.721 ; \mathrm{p}=0.190\right)$, season $\left(\chi^{2}=2.661 ; \mathrm{p}=0.264\right)$, locality $\left(\chi^{2}=7.66 ; \mathrm{p}=0.264\right)$, parity number $\left(\chi^{2}=0.451 ; \mathrm{p}=0.767\right)$, and rearing system $\left(\chi^{2}=1.593 ; \mathrm{p}=0.451\right)$ were not significantly associated with pseudopregnancy.
\end{abstract}

Conclusion: The prevalence of pseudopregnancy in goats in Khartoum State was 10.6\%. Pseudopregnancy in goats is significantly associated with age, type of estrus, general body condition, and previous reproductive performance. This study showed for the first time that pseudopregnancy is a real reproductive problem in goats in Khartoum State.

Keywords: goat, hydrometra, prevalence, risk factors, Sudan, ultrasound.

\section{Introduction}

During the last decade, interest in goats has increased worldwide due to their importance in agricultural systems in low-income countries and an increased demand for goat products in developed countries [1]. Sudan possesses over 100 million head of livestock population; among this population, the estimated population of goats is about 31 million head [2]. This population figure puts Sudan as a leading livestock producer in Africa and Arab countries [3].

As reproduction is the backbone of the animal production chain, it is essential to increase the reproduction efficiency in goats [4]. Reproductive ultrasonography in small ruminants is the most efficient diagnostic tool for managing reproduction [5]. It has revolutionized

Copyright: Almubarak, et al. Open Access. This article is distributed under the terms of the Creative Commons Attribution 4.0 International License (http://creativecommons.org/licenses/ by/4.0/), which permits unrestricted use, distribution, and reproduction in any medium, provided you give appropriate credit to the original author(s) and the source, provide a link to the Creative Commons license, and indicate if changes were made. The Creative Commons Public Domain Dedication waiver (http:// creativecommons.org/publicdomain/zero/1.0/) applies to the data made available in this article, unless otherwise stated. the knowledge of reproductive technology [6]. B-mode ultrasound is used on a large scale to monitor reproductive status in small ruminants. It is considered a simple, non-invasive, rapid, and reliable method for detecting pregnancy, estimating litter size and fetal weight, and determining gestational age [7-9]. It is useful in the diagnosis of pathological conditions that reduce fertility and reproductive performance in females such as pseudopregnancy, pyometra, ovarian cysts, and metritis $[5,10]$. Pseudopregnancy is an anestrus condition in which fluid accumulates inside the uterus with the persistence of corpus luteum (CL) and absence of fetus and/or placentomes [10-12]. It is an important pathological condition because it causes temporary infertility in dairy goats [13], and it is the most common uterine pathology affecting fertility $[5,14]$. Hydrometra and mucometra are the terms used as synonymous with pseudopregnancy in goats [15]. The etiology and pathophysiology of the condition are not well clarified [16,17]. It is always associated with high plasma progesterone level secreted by a persistent functional CL, cessation of cyclical activity, and a variable degree of abdominal distension [18]. 
The condition is incidentally found during routine pregnancy diagnosis of mated animals. However, it also occurs in unmated anestrus does during the breeding and non-breeding seasons [16,19]. Hydrometra in goats has been associated with disturbances in either luteotrophic or luteolytic mechanism during the ovarian cycle. Moreover, prolactin may also be associated with the development of hydrometra in goats $[19,20]$.

In temperate areas, the incidence of hydrometra in goats varies between $3.0 \%$ and $20.8 \%$ [21]. The incidence of hydrometra increases with milk yield and age of the dam and may accompany fetal death $[16,21,22]$. Hydrometra in goats has also been predisposed by genetics as reported by Hesselink and Elving [23]. In tropics, reports of pseudopregnancy are scarce [24]. In Sudan, only two cases of hydrometra have been reported in goats $[25,26]$; however, the prevalence and potential risk factors associated with pseudopregnancy in goats are unknown. Hence, the present study was conducted in Khartoum State of Sudan to determine the prevalence and associated risk factors of pseudopregnancy in goats.

\section{Materials and Methods}

\section{Ethical approval}

The study was approved by the Research Committee of the College of Veterinary Medicine, Sudan University of Science and Technology (SUST).

\section{Study area}

The present study was carried out at the Veterinary Teaching Hospital (VTH), College of Veterinary Medicine, SUST, Hilat Kuku, Khartoum North. The VTH received goats from all localities of Khartoum State for routine sonographic pregnancy diagnosis; therefore, it was selected for the present study.

Khartoum State lies in central Sudan in the semiarid zone between latitude $15^{\circ} 32.799^{\prime} \mathrm{N}$ and longitude $32^{\circ} 32.0166^{\prime} \mathrm{E}$ in an area about $28.165 \mathrm{~km}^{2}$. The average annual temperature in Khartoum State ranges between $22.7^{\circ} \mathrm{C}$ and $37.1^{\circ} \mathrm{C}$, with a mean annual rainfall of $156.8 \mathrm{~mm}$. Geographically, Khartoum State is divided into seven localities, namely Khartoum, Jebal Aulya, Khartoum Bahri, Sharg El Nile, Um Durman, Karari, and Um Badah. The goat population in Khartoum State is around 651,052 [2].

\section{Study design, animals, and duration}

This cross-sectional study was conducted from March 2015 to February 2016. A total of 378 does of different breeds with ages between 6 months and 14 years were included in the study. All goats were put into general health status categories as poor, moderate, and good. Age was determined according to the date of birth (if known) or by using dentition formula according to Smith and Sherman [1]. Sample size was calculated based on $30.4 \%$ prevalence reported by Lopes et al. [24] and 95\% confidence interval and 5\% desired precision according to Thrusfield [27]. A pre-tested questionnaire was developed, and all data related to the study objectives were recorded including breed, age, milk production, rearing system, type of feeding, type of estrus, parity number, general body condition, previous reproductive performance, locality, type of insemination, and season.

\section{Ultrasound technique}

Ultrasound scanning was conducted using B-mode real-time scanner (Aquila Vet, Pie medical Easote, the Netherlands) equipped with a dual-frequency $(3.5-5 \mathrm{MHz})$ transabdominal curvilinear probe. Animals were put in a supine position on a specially designed table. Sufficient amount of ultrasonic gel was applied to the shaved ventral abdomen before scanning as described by Goddard [28]. Sonographic pictures were printed on thermal papers (Sony Corporation, Type 1, Normal, UPP-110S, 1-71, Konan, Minato-KU, Tokyo, Japan) using a video graphic printer UP-895EC (Sony Co. Tokyo, Japan).

\section{Statistical analysis}

Statistical analysis was performed using the Statistical Package for the Social Sciences (SPSS) version 22.0 (SPSS Inc., Chicago, USA). Descriptive statistics of the variables were obtained. Univariate analysis using Chi-square test was done to determine whether pseudopregnancy prevalence differed significantly between the levels of selected risk factors. $\mathrm{p} \leq 0.05$ was considered statistically significant.

\section{Results}

\section{Prevalence and risk factors}

In the present study, 40 out of 378 examined goats in Khartoum State were diagnosed with pseudopregnancy, i.e. $10.6 \%$ prevalence proportion. The prevalence of pseudopregnancy increased with age $\left(\chi^{2}=11.760\right.$; $\mathrm{p}=0.0129)$. Does with induced estrus were highly associated with pseudopregnancy $\left(\chi^{2}=12.794 ; \mathrm{p}=0.000\right)$.

Furthermore, a significant association $\left(\chi^{2}=13.397\right.$; $\mathrm{p}=0.020$ ) was found between the previous history of the dam and pseudopregnancy; 21/221 (9.5\%) were diagnosed among goats with no previous reproductive problems, while $8 / 26(30.8 \%)$ had a previous history of pseudopregnancy.

Our study also showed a significant association $\left(\chi^{2}=5.974 ; p=0.05\right)$ between the prevalence of pseudopregnancy and the general condition of the dam. Out of 292 goats with good body condition, 37 (12.7\%) were diagnosed pseudopregnant. Three (3.7\%) out of 82 goats of moderately body condition were diagnosed as pseudopregnant. Pseudopregnancy was not diagnosed among goats with the poor body condition.

Results of the present study showed that milk yield $\left(\chi^{2}=5.951 ; \mathrm{p}=0.114\right)$, breed of the goat $\left(\chi^{2}=12.627\right.$; $\mathrm{p}=0.082)$, type of feeding $\left(\chi^{2}=1.721 ; \mathrm{p}=0.190\right)$, season $\left(\chi^{2}=2.661 ; \mathrm{p}=0.264\right)$, locality $\left(\chi^{2}=7.66 ; \mathrm{p}=0.264\right)$, parity number $\left(\chi^{2}=0.451 ; \mathrm{p}=0.767\right)$, and rearing system $\left(\chi^{2}=1.593 ; \mathrm{p}=0.451\right)$ were not significantly associated with pseudopregnancy (Table-1). One risk factor (type of insemination) was not subjected to statistical 
Table-1: Univariate analysis of the association of potential risk factors with pseudopregnancy in goats using the Chi-square test.

\begin{tabular}{|c|c|c|c|c|c|}
\hline Factor & Number of examined & Number of positives (\%) & df & $\chi^{2}$ & $\mathbf{p}$ \\
\hline \multicolumn{6}{|l|}{ Season } \\
\hline Summer & 100 & $8(8)$ & 2 & 2.661 & 0.264 \\
\hline Autumn & 136 & $19(14)$ & & & \\
\hline Winter & 142 & $13(9.2)$ & & & \\
\hline \multicolumn{6}{|l|}{ Locality } \\
\hline Karari & 116 & $12(10.3)$ & 6 & 7.66 & 0.264 \\
\hline Um Badah & 38 & $5(13.2)$ & & & \\
\hline Um Durman & 18 & $2(11.1)$ & & & \\
\hline Sharg El Nile & 123 & $8(6.5)$ & & & \\
\hline Khartoum Bahri & 37 & $4(10.8)$ & & & \\
\hline Khartoum & 30 & $7(23.3)$ & & & \\
\hline Jebal Aulya & 16 & $2(12.5)$ & & & \\
\hline \multicolumn{6}{|l|}{ Breed } \\
\hline Saanen & 226 & $34(15)$ & 7 & 12.627 & 0.082 \\
\hline Damascus & 64 & $2(3.1)$ & & & \\
\hline Nubian & 33 & $1(3)$ & & & \\
\hline Desert & 13 & $1(7.7)$ & & & \\
\hline Anglonubian & 4 & $0(0)$ & & & \\
\hline Toggenburg & 4 & $0(0)$ & & & \\
\hline Damascus $\times$ Saanen & 28 & $2(7.1)$ & & & \\
\hline American & 6 & $0(0)$ & & & \\
\hline \multicolumn{6}{|l|}{ General body condition } \\
\hline Poor & 4 & $0(0 \%)$ & 2 & 5.974 & $0.050 *$ \\
\hline Good & 292 & $37(12.7 \%)$ & & & \\
\hline Moderate & 82 & $3(3.7 \%)$ & & & \\
\hline \multicolumn{6}{|l|}{ Age (years) } \\
\hline $0.5-2$ & 161 & $14(8.7)$ & 4 & 11.760 & $0.019 *$ \\
\hline$>2-4$ & 156 & $14(9)$ & & & \\
\hline$>4-6$ & 39 & $5(12.8)$ & & & \\
\hline$>6-8$ & 13 & $4(30.8)$ & & & \\
\hline$>8$ & 9 & $3(33.3)$ & & & \\
\hline \multicolumn{6}{|l|}{ Type of estrus } \\
\hline Natural & 362 & $34(9.4)$ & 1 & 12.794 & $0.000^{*}$ \\
\hline Induced & 16 & $6(37.5)$ & & & \\
\hline \multicolumn{6}{|l|}{ Milk yield } \\
\hline 0 & 111 & $11(9.9)$ & 3 & 5.951 & 0.114 \\
\hline $0.5-3$ & 74 & $4(5.4)$ & & & \\
\hline$>3-6$ & 104 & $10(9.6)$ & & & \\
\hline$>6$ & 89 & $15(16.9)$ & & & \\
\hline \multicolumn{6}{|l|}{ Parity } \\
\hline Nulliparous & 112 & $11(9.8)$ & 2 & 0.351 & 0.767 \\
\hline Primiparous & 78 & $7(9)$ & & & \\
\hline Multiparous & 188 & $22(11.7)$ & & & \\
\hline \multicolumn{6}{|l|}{ Previous history } \\
\hline Normal & 221 & $21(9.5)$ & 5 & 13.397 & $0.020 *$ \\
\hline Pseudopregnancy & 26 & $8(30.8)$ & & & \\
\hline Abortion & 30 & $1(3.3)$ & & & \\
\hline Dystocia & 1 & $0(0)$ & & & \\
\hline Stillbirth & 1 & $0(0)$ & & & \\
\hline No history & 99 & $10(10.1)$ & & & \\
\hline \multicolumn{6}{|l|}{ Rearing system } \\
\hline Open & 3 & $0(0)$ & 2 & 1.593 & 0.451 \\
\hline Close & 365 & $40(11)$ & & & \\
\hline Mixed & 10 & $0(0)$ & & & \\
\hline \multicolumn{6}{|l|}{ Type of feeding } \\
\hline Green fodder & 14 & $0(0)$ & 1 & 1.721 & 0.190 \\
\hline Mixed & 364 & $40(11)$ & & & \\
\hline
\end{tabular}

$*_{p} \leq 0.05$ was considered as statistically significant, $\mathrm{df}=$ degree of freedom

analysis because all animals in the present study were naturally mated (constant parameter).

\section{Discussion}

Pseudopregnancy is a pathological condition characterized by the accumulation of aseptic fluid in uterine lumen with persistence of a functional $\mathrm{CL}$, a variable degree of abdominal distension, and cessation of cyclical activity $[18,19,21]$. The pathophysiology of the condition is not well understood $[16,17]$. Diagnosis of pseudopregnancy can easily be made by ultrasound $[19,21]$. The sonographic diagnosis of 
pseudopregnancy is based on recognition of fluid in the uterus in the absence of fetuses and placentomes [10].

To the best of the author's knowledge, this is the first study to investigate and report the prevalence of pseudopregnancy in goats from Sudan and the African continent. In the present study, the prevalence of pseudopregnancy in Khartoum State was found to be $10.6 \%$. Hesselink and Elving [23] reported a prevalence of $10.4 \%$ during four estrus seasons in white Dutch dairy goats in the Netherlands. In Brazil, a higher percentage $(12.4 \%)$ was reported in Toggenburg and Saanen breeds by Souza et al. [13]. In the Netherlands, slightly lower prevalence (9\%) was found in Saanen goats by Hesselink [21]. An incidence of 3.26\% was reported by Batista et al. [29] in Canary Island goats. Nevertheless, in Brazil, a higher prevalence $(30.4 \%)$ was found in Saanen goats by Lopes et al. [24]. The difference among these studies could be due to differences in environmental conditions, management, and breed of the animals.

The results of the present study showed highly significant association $(\mathrm{p}=0.000)$ between the type of estrus cycle and pseudopregnancy. Similar findings were reported by Batista et al. [29], who observed higher frequency in goats made to ovulate using hormonal treatments. Their study reported that, regardless of the season of the year, treatment of the goats with progesterone favored the development of hydrometra. Our findings are also in line with Wittek et al. [16], who found the higher frequency in does which had been mated after estrus synchronization with progesterone and pregnant mare serum gonadotropin. Conflicting results have been obtained by Moraes et al. [22], who reported 9\% pseudopregnancy in goats that were not subjected to any hormonal treatment for estrus induction.

An increase of pseudopregnancy proportion with age was reported in our study $(p=0.019)$. High frequency in elder goats was reported by Wittek et al. [16], Hesselink [21], and Batista et al. [29], and this is in agreement with the present findings. Concerning the former pathological history of examined goats, the high prevalence of pseudopregnancy $(30.8 \%)$ was found in goats with the previous report of pseudopregnancy $(\mathrm{p}=0.020)$. Similar findings were obtained by Wittek et al. [16], who examined a herd of 2434 goats and reported that pseudopregnant goats showed a high risk of developing hydrometra again. Also, a significant association $(\mathrm{p}=0.05)$ was found between the general body condition of the goat and pseudopregnancy.

Our study revealed no significant association $(p=0.082)$ between the breed and pseudopregnancy. These findings are in agreement with Wittek et al. [16] who reported that the breed of the goats did not influence the incidence of hydrometra. However, it is particularly interesting that the higher prevalence of pseudopregnancy was found in Saanen goats and their crosses. A previous study identified pseudopregnancy as a major problem of Saanen breed raised in northeast part of Brazil [24]. They found that the problem is exacerbated because of lack of ultrasonographic diagnosis in the farms. Batista et al. [29] reported that a genetic predisposition might have a role in the high incidence of hydrometra. Moreover, Hesselink and Elving [23] reported a high frequency of hydrometra in daughters of pseudopregnant does of Saanen herd in the Netherlands.

Milk yield was not associated significantly with pseudopregnancy in the present study $(\mathrm{p}=0.114)$. This finding is in line with Wittek et al. [16] who reported that milk yield did not influence the incidence of hydrometra. On the contrary, Hesselink [21] and Moraes et al. [22] found that the high incidence of pseudopregnancy was associated with increased milk yield.

Based on our data, the season was not a significant risk factor for hydrometra $(\mathrm{p}=0.264)$. This agrees with previous research of Hesselink and Taverne [10] and Taverne et al. [19] who reported that the condition occurs both outside and during the breeding season. In contrast, Wittek et al. [16] recorded higher incidence of hydrometra out of the breeding season. This variation could be due to the difference in climatic factors; the previous studies were from temperate regions where goats tend to breed only seasonally, with the breeding season being from July/August to November/December [30]. However, in the tropical zones, goats tend to breed throughout the year [12].

According to the present study, there was no significant association $(p=0.767)$ between parity number and pseudopregnancy. However, pseudopregnancy was diagnosed with a considerable percentage $(27.5 \%)$ in nulliparous goats. On the contrary, Batista et al. [29] reported 43/1321 (3.26\%) pseudopregnancy in goats and all of them had kidded at least once.

According to our observations, feeding type and rearing system do not influence the occurrence of pseudopregnancy. These findings agree with Moraes et al. [22] who reported that nutritional management and rearing system do not influence the occurrence of pseudopregnancy. Furthermore, no significant association $(p=0.264)$ was found between the locality and pseudopregnancy. Pseudopregnancy was reported from all localities of Khartoum State. The absence of an association between location and pseudopregnancy could be due to the relative similarity in agro-ecology and management systems between the study locations.

\section{Conclusion}

It can be concluded that the prevalence of pseudopregnancy in goats in Khartoum State was $10.6 \%$. This study also showed that pseudopregnancy in goats significantly associated with age, type of estrus, general body condition, and previous reproductive performance.

\section{Authors' Contributions}

AMA conducted the experimental work (ultrasound scanning) and drafting of the manuscript. RMA 
and MEB supervised the experimental work and revised the manuscript. NAA helped in data entering, interpretation of the results, and revision of the manuscript. MTI conducted the statistical analysis. AAE designed this study and involved in the manuscript revision. All authors read and approved the final manuscript.

\section{Acknowledgments}

We are grateful to Professor Ahmed Abdelrahim Gameel, Faculty of Veterinary Medicine, University of Khartoum, for his valuable suggestions and comments. This study was funded by the German Academic Exchange Service (DAAD), in-country scholarship program Sudan, 2015 (57191503).

\section{Competing Interests} interests.

The authors declare that they have no competing

\section{References}

1. Smith, M.C. and Sherman, D.M. (2009) Goat Medicine. $2^{\text {nd }}$ ed. Wiley-Blackwell, USA. p871.

2. MOAR. (2012) Ministry of Animal Resources-Information Center. Estimate of Livestock Population by States. Khartoum, Sudan.

3. Elrasheed, M.M., Faki, H.M. and Elobied, H.A. (2010) Desert sheep in Kordofan Area-Sudan: Production and marketing. J. Sci. Tech., 11: 17-22.

4. Greyling, J. (2010) Applied reproductive physiology. In: Solaiman, S.G., editor. Goat Science and Production. $1^{\text {st }}$ ed. Wiley-Blackwell, USA. p140-155.

5. Gonzalez-Bulnes, A., Pallares, P., Vazquez, M. (2010) Ultrasonographic imaging in small ruminant reproduction. Reprod. Domest. Anim., 45: 9-20.

6. Medan, M.S. and Abd-El-Aty, A.M. (2010) Advances in ultrasonography and its applications in domestic ruminants and other farm animals reproduction. J. Adv. Res., 1: $123-128$.

7. Santiago-Moreno, J., Gonzalez-Bulnes, A., Gomes-Brunet, A., Toledano-Diaz, A. and Lopez-Sebastian, A. (2005) Prediction of gestational age by transrectal ultrasonographic measurements in the Mouflon (Ovis gmelini musimon). J. Zoo Wildl Med., 36: 457-462.

8. Azevedo, E., Aguair, F.C., Freitas, N.L., Robelo, M., Santos, M., Lima, B., Freitas, V. and Oliveira, M. (2007) Ultrasound fetal measurement parameters for early estimate of gestational age and birth weight in ewe. Med. Vet., 1: $56-61$.

9. Godfrey, R.W., Larson, L., Weis, A.J. and. Willard, S.T. (2010) Evaluation of ultrasonography to measure fetal size and heart rate as predictors of fetal age in hair sheep. Sheep Goat Res. J., 25: 60-65.

10. Hesselink, J.W. and Taverne, M.A. (1994) Ultrasonography of the uterus of the goat. Vet. Q., 16: 41-45.

11. Pieteres, M.C. and Taverne, M.A. (1986) Hydrometra in goats: Diagnosis with real-time ultrasound and treatment with prostaglandins or oxytocin. Theriogenology, 26: 813-821.

12. Hafez, B. and Hafez, E. (2000) Reproduction in Farm Animals. $7^{\text {th }}$ ed. Lippincott William \&Wilkins, USA.

13. Souza, JM., Maia, A.L., Brandao, F.Z., Vilela, C.G., Oba, E., Bruschi, J.H. and Fonseca, J.F. (2013) Hormonal treatment of dairy goats affected by hydrometra associated or not with ovarian follicular cyst. Small Rumin. Res., 111: 104-109.

14. Kornalijnslijper, J.E., Bevers, M.M., Van Oord, H.A. and Taverne, M.A. (1997a) Induction of hydrometra in goats by means of active immunization against prostaglandin $\mathrm{F} 2 \alpha$. Anim. Reprod. Sci., 46: 109-122.

15. Reddy, R., Arunakumari, G., Anil, K.R., Muralimohan, K. and Sunil, A. (2014) Efficacy of cloprostenol therapy in hydrometra goats. Indian J. Anim. Reprod., 35: 39-41.

16. Wittek, T., Richter, A., Erices, J. and Elze, K. (1997) Incidence, diagnosis, therapy and subsequent fertility in goats with hydrometra. Tierarztl. Prax., 25: 576-582.

17. Purohit, G.N. and Mehta, J.S. (2012) Hydrometra in goats (Capra hircus): Clinical analysis of 26 cases. Rumin. Sci., 1: $117-119$.

18. Noakes, D.E., Parkinson, T.J. and England, G.C. (2009) Veterinary Reproduction and Obstetrics. $9^{\text {th }}$ ed. W. B. Saunders, Elsevier, USA.

19. Taverne, M.A., Hesselink, J.W., Bevers, M.M., Van Oord, H.A. and Kornalijnslijper, J.E. (1995) Aetiology and endocrinology of pseudopregnancy in the Goat. Reprod. Domest. Anim., 30: 228-230.

20. Kornalijnslijper, J.E., Kemp, B., Bevers, M.M., Van Oord, H.A. and Taverne, M.A. (1997b) Plasma prolactin, growth hormone and progesterone concentration in pseudopregnant, hysterectomized and pregnant goats. Anim. Reprod. Sci., 49: 169-178.

21. Hesselink, J.W. (1993) Incidence of hydrometra in dairy goats. Vet. Rec., 132: 110-112.

22. Moraes, W.P., Santos, M.H., Arruda, I.J., Bezerra, F.Q., Aguiar, F.C.R., Neves, J.P., Lima, P.F. and Oliveira, M. (2007) Hydrometra and mucometra in goats diagnosed by ultrasound and treated with PGF2 $\alpha$. Med. Vet., 1: 33-39.

23. Hesselink, J.W. and Elving, L. (1996) Pedigree analysis in a herd of dairy goats with respect to the incidence of hydrometra. Vet. Q., 18: 24-25.

24. Lopes, E.S. Jr., Cruz, J.F., Teixeira, D.I., Lima, V.J.B., Paula, N.R., Rodnina, D. and Freitas, V.J. (2004) Pseudopregnancy in Saanen goats (Capra hircus) raised in Northeast Brazil. Vet. Res. Commun., 28: 119-125.

25. Ahmed, B.H., Hamad, R.J. and Abdelghafar, R.M. (2010) Ultrasonography for diagnosis of hydrometra and pyometra (two case reports). Assiut Vet. Med. J., 56: 225-230.

26. Almubarak, A.M., Abdelghafar, R.M. and Badawi, M.E. (2016) Hydrometra in a goat-diagnosis, treatment and subsequent fertility. Int. J. Livestock Res., 6: 114-118

27. Thrusfield, M. (2007) Veterinary Epidemiology. $3^{\text {rd }}$ ed. Black Well, Oxford. UK.

28. Goddard, P.J. (1996) Veterinary Ultrasonography. Cab International. Wallingford, Oxon OXI0 8DE. UK. p329.

29. Batista, M., Medina, J., Calero, P., Gonzalez, F., Quesada, E. and Gracia, A. (2001) Incidence and treatment of hydrometra in canary island goats. Vet. Rec., 149: 329-330.

30. Solaiman, S.G. (2010) Goat Science and Production. $1^{\text {st }}$ ed. Wiley-Blackwell, USA. p425. 